\title{
Medios, legitimidad y negociación popular. Una mirada al fenómeno chileno de la televisión
}

\author{
Felipe LAGOS*
}

La televisión se ha convertido en el mass media por excelencia debido la eficiencia de su alcance: no sólo ha centrado hoy sus mecanismos de captación de audiencias en una televisionización de sus contenidos, sino que ha conducido a otros medios a establecer diálogos con su programación.

Esta (auto)referencialidad asume hoy contornos distintivos que se pueden observar como nueva estrategia mediática. Las estrategias mediáticas son para Bendezú "programas para regular el intercambio comunicacional que en los medios de comunicación informativos, como en los demás, es la credibilidad"1. Básico para el éxito actual de la televisión como dispositivo es entonces el que los contenidos propuestos en el flujo de comunicación sean aceptados como verosímiles.

Esto permite comprender el que uno de los principales soportes de las estrategias mediáticas televisivas haya consistido en la "trivialización" de sus contenidos: la televisión tiende a re-presentar, a poner en escena, situaciones y experiencias que pueden ser reconocidas como parte de la vida cotidiana, sea la vida propia o de grupos que poseen significación en la vida cultural que reconozco, pero de los que no formo parte. La representación de realidad vivida, reconocible y articulable en el lenguaje, es lo que Brunner denominó la "estrategia del común denominador".

El Informe 2004 para Chile del Programa de las Naciones Unidas para el Desarrollo (PNUD), en su "Índice de alianza con los medios", dice que la mayor parte de los sectores bajos y medios-bajos del espacio urbano, y la práctica generalidad del mundo rural, opinan que los mass media han cambiado "para mejor"; por otra parte, la clase alta y urbana observa que la degradación de los medios en relación con la "cotidianización" de sus mensajes, valorando la diversificación pero condenando la "chabacanería": el cambio de los mass media como reflejos de una alta cultura, a la cotidianización de la cultura mediática es, en estas sentencias, evidente ${ }^{2}$.

A su vez, los estudios del Consejo Nacional de Televisión (CNTV) muestran que el período 2002-2005 la percepción de "contenidos inadecuados" en televisión ha crecido de un $44,5 \%$ a un $57,5 \%$, siendo más proclives a esta opinión las mujeres de estrato bajo ${ }^{3}$. Esto da cuenta de una tendencia hacia la hiper representación de ciertas situaciones de la vida cotidiana. La televisión operaría, en términos de Arfuch "salta(ndo) la valla que va de la narración de un suceso de la propia vida a su actuación directa en la pantalla (...) la desaparición de toda mediación en aras del acontecimiento en estado puro"

Los estudios culturales latinoamericanos han asumido como tendencia la observación de que los sectores populares tienen capacidad de negociar en el diálogo

\footnotetext{
* Licenciado en Sociología, Facultad de Ciencias Sociales, Universidad de Chile. Candidato a Magíster en Estudios Latinoamericanos, Facultad de Filosofía y Humanidades, Universidad de Chile.

${ }^{1}$ OSSA, Carlos (comp.) "La Pantalla Delirante. Nuevos escenarios de la comunicación en Chile". LOM Ediciones. Santiago de Chile. 2001. Artículo de Raúl Bendezú: "La espectacularización mediática".

${ }^{2}$ Programa de las Naciones Unidas para el Desarrollo. Informes de Desarrollo Humano en Chile. "El Poder: ¿para qué y para quién?”. Santiago de Chile. 2004.

${ }^{3}$ CNTV, Consejo Nacional de Televisión. "Estudio Estadístico de Televisión Abierta 2000 - 2005". 2005. Disponible en http://www.cntv.cl/medios/Publicaciones/2005/Estadistico2005.pdf.

${ }^{4}$ ARFUCH, Leonor. "Lo Público y lo Privado en la Escena Contemporánea: política y subjetividad", en Revista de Crítica Cultural, N ${ }^{\circ}$ 21, Dossier: Lo Público y lo Privado. Editorial Cuarto Propio. Santiago de Chile. 2000.
} 
que se articula entre la representación del flujo estructurado que se dirige a ellos a través de los medios, y sus propios procesos de decodificación. El objetivo de este artículo consiste en problematizar el contenido de esta idea, compartiendo el supuesto de que los espacios de manifestación de la cultura de masas, en tanto espacios de disputa hegemónica por el sentido de la vida social, nos hablan de la cultura política de una sociedad.

Hay una pregunta anterior sin embargo, que sólo dejaremos enunciada: ¿Debe resultar claro que, ante la pregunta por los mass media, se piense en forma paradigmática en la televisión? Pensamos que sí. Esta extensión figurativa no se da sólo en este plano, sino que se extiende al campo de la política partidaria. Conocidos son los planteamientos del politólogo Giovanni Sartori sobre la irrupción de la "videopolítica" como el espacio de la escenificación del gesto político por sobre el contenido programático. Y hoy, lo más probable es que, cuando preguntemos sobre política a un transeúnte, su respuesta esté informada por la edición que de tal tema, imagen o discurso, ha hecho una estación televisiva (o, en menor medida, la prensa escrita ${ }^{5}$ ).

Una pista para la extensión del fenómeno la da Martín-Barbero: “de una punta a otra del espectro cultural el flujo expresa la disolvencia de los géneros y la exaltación expresiva de lo efímero (...) pues al proponer la equivalencia de todos los discursos información, drama, ciencia, pornografía o datos financieros- y la interpenetrabilidad de todos los géneros, nos encontramos ante la exaltación de lo móvil y difuso, de la carencia de clausura y la indeterminación temporal como clave de producción y propuesta de goce estético" ". Pongo el acento en la equivalencia de los discursos y contenidos, que en el párrafo citado proviene de un diagnóstico de los flujos globalizados, y que sirven como recursos formales de los mass media. Parafraseando a Virilo, diríamos que estos discursos son hiper representados en su equivalencia, consistiendo ésta una estrategia de semantización, de representación pública de la realidad. Ese espacio de representación es el que creemos exacerbado en la televisión.

\section{Televisión como dispositivo de integración}

La idea de mass media es indisociable de la idea de industria cultural. Cuando se describe el proceso de conformación de las economías nacionales como proyecto nación, de lo que damos cuenta es la conjunción como proyecto entre los desafíos de consolidación de una estrategia de desarrollo centrada en la generación de un mercado interno diversificado, y de la producción de una nación autoidentificada culturalmente como tal. Nación que, ciertamente, se identifica en tanto partícipe de los mecanismos de consumo culturales, tanto como en su ingreso a los ámbitos formales de participación política y social.

La resolución de la crisis política latinoamericana de fines de los '60 e inicios de los '70 (golpes militares de Estado mediante) y la posterior puesta en marcha en Chile de políticas cuya finalidad se centra en reorganizar el conjunto de la vida social, no tiene que ver sólo con la imposición de un modelo de regulación económica; se trata de una imbricación entre los resultados del proyecto de refundación neoliberal y sus contraculturas (políticas o socio-culturales) en el marco de un macro-proceso de vertiginosa globalización tecnológico-cultural.

\footnotetext{
${ }^{5}$ La encuesta "Medios Masivos y Elites Políticas" del Instituto de Ciencias Sociales de la Universidad Diego Portales, constituye una buena representación de lo dicho.

${ }^{6}$ OSSA, C. (comp.) Op. Cit. Artículo de Jesús Martín-Barbero: "Los descentramientos del arte y la comunicación".
} 
Estos tres ejes del proceso permiten hacer comprensible la articulación de un denso espacio donde, en palabras de Brunner, "los principales dispositivos de articulación hegemónica de cada una de esas conformaciones se oponen pero, a la vez, se entrecruzan y entremezclan, dando lugar progresivamente a un universo cultural conflictivo, compuesto por sectores mal soldados entre sí, lleno de tensiones, que mantiene una separación de todos los elementos según su afiliación a una u otra de esas conformaciones sin poder evitar, con todo, que ellos se entreveren en la práctica cotidiana de la sociedad". Hay una interconexión entre los intentos de reconfigurar nuevas prácticas sobre la base de la proyección de una sociedad conceptuada como totalidad democrática, con una serie de dispositivos que transforman los espacios que hacían posibles esas prácticas por otras constelaciones culturales más propias de la modernidad capitalista tardía: "lo que reveló esa etapa (...) es que esa cultura oposicional no es resistente frente a los movimientos más profundos de la cultura de masas", , cultura definida como superación de los tipos tradicionales de públicos orgánicos.

En este contexto de re-significaciones tecnológicas y culturales, los mass media se mueven en una doble paradoja: la primera está del lado del control de su emisión:

- Por un lado, los mass media formatean las representaciones sociales que legitiman el orden social de dominación, semantizando las posibilidades de una sociedad de asegurar su propia integración en términos afirmativos; como consecuencia de ello, son funcionales (como dispositivos) a los actores dominantes de una formación social $^{8}$;

- Por otro lado, la globalización mercantil y tecnológica, y sus consecuencias en competitividad y riesgo asociado a ella, hace que los mass media tiendan a autonomizarse del control sobre contenidos concretos que pueden imprimirle estos actores dominantes, para asumir formatos y contenidos "probados" y "en sintonía" con la globalización cultural e informacional.

Del "lado del receptor", en tanto:

- Le es re-presentada un realidad semantizada como coherente y monolítica, de una sola dimensión (la del mercado); realidad legítima, que instala la necesidad del "consumo del proceso de consumo" de la producción social: la idea de que se puede "acceder a" (consumir, no producir) un presente-futuro compartido; en este sentido, permiten acceder a una "realidad" homogénea.

- Le es re-presentada una realidad coherente en su fragmentariedad, es decir, correspondiente con el proceso de búsqueda que asume el individuo des-centrado y ansioso: las imágenes del miedo al otro y del hedonismo exacerbado dinamizan la diferenciación simbólica; ${ }^{10}$

\footnotetext{
${ }^{7}$ BRÜNNER, José Joaquín: "Un Espejo Trizado. Ensayos sobre cultura y políticas culturales”. FLACSO. Santiago de Chile. 1988.

${ }^{8}$ Este punto de la hipótesis es desarrollado por Marcuse en su célebre recensión sobre el carácter de proyecto político de toda constelación tecnológica. La teoría sistémica de la comunicación mediática tributaria del funcionalismo radical de Luhmann, por su lado, trabaja el problema desde el concepto de reducción de complejidad.

${ }^{9}$ ZIZEK, Slavoj (comp.): "Ideología. Un mapa de la cuestión". Editorial Fondo de Cultura Económica. México D.F. 1994. Artículo de Frederic Jameson. "La Posmodernidad y el Mercado".

10 Volvemos a Marcuse, quien mediante un análisis dialéctico permite comprender la sociedad unidimensional como la doble lógica de homogeneización y diversificación cultural operante en base al "cierre" de los universos político (identificación de los contrarios en el plano de proyectos de sociedad, en el marco de la post-guerra fría) y discursivo (pérdida de capacidad negativa del concepto). Para dar cuenta de ello, propone su concepto de "tolerancia represiva". Ver "El Hombre Unidimensional". Editorial SeixBarral. Barcelona. 1968.
} 
Thompson advierte sobre dos peligros de los conceptos de comunicación de masas, o el más común de cultura de masas: el considerar la audiencia como siempre amplia, abarcante de un conjunto significativo de personas de una población determinada; y considerar a la masa como un mar de individuos pasivos e indiferenciados. Sugiere Thompson (y en ello lo seguiremos) hablar de comunicación mediática, como "producción institucionalizada y difusión generalizada de bienes simbólicos a través de la fijación y transmisión de información o contenido simbólico. Desglosaré esta definición en cinco características: los medios técnicos e institucionales de producción y difusión; la producción de formas simbólicas de consumo; la ruptura estructurada entre producción y recepción; la creciente disponibilidad de los productos mediáticos en el tiempo y el espacio; y la circulación pública de las formas simbólicas mediáticas" $"$.

El estudio sobre la comunicación debe ser contextual, esto es, ser considerado como parte integral de contextos más amplios de la vida social. Por ende, en la actual comunicación mediática se deben resaltar dos consecuencias de la ruptura estructurada entre producción y recepción:

- los productos mediáticos están, en principio, disponibles para una "pluralidad" de receptores; en ello consiste su carácter potencialmente masivo, lo que no quiere decir que ello constituya efectivamente públicos;

- dicha ruptura estructurada permite una articulación mayor del flujo estructurado, esto es, una transformación en las interacciones productor-receptor; el receptor, en este contexto, tiene menos capacidad para entrar en diálogo con el productor con el fin de intencionar la producción mediática misma.

Thompson considera que la estructura del flujo nunca es unidimensional, que para garantizar el proceso de codificación-decodificación, siempre debe haber algún nivel de capacidad del receptor para intervenir la estructura de comunicación propuesta; por ejemplo, en los diálogos esa capacidad es prácticamente simétrica. Por ende, es la estructura contextual de comunicación imperante, la que permite dimensionar el carácter real o ilusorio de la participación y/o negociación en la producción de los mensajes mediáticos.

\section{Sociedad civil y espacio público de representación}

La condición de dispositivo hegemónico adscrita a los mass media, y en especial a la televisión, toma su capacidad de legitimar un orden de dominación en ser a la vez productores y producto, de la des-territorialización de las identidades sociales, en tanto desanclan estas identidades del espacio geopolítico que conforma una nación, y que había sido la base del tipo de comunidad imaginaria característica del ser "moderno": "para el avance de la cultura empresarial ha sido necesario redefinir la distribución material del poder en la cultura (...) los medios masivos de comunicación se convierten en el modelador principal de las nuevas identidades"12.

Es el noticiario televisivo el que configura, en términos generales, la "opinión nacional", con mayor aceptación de esta sentencia en el Gran Santiago que en regiones. El CNTV da cuenta de la importancia estable del rol televisivo en la información sobre el acontecer nacional, en contraste, por ejemplo, de las variaciones en torno a su rol

\footnotetext{
11 THOMPSON, John B.: "Los Media y la Modernidad: una teoría de los medios de comunicación". Editorial Paidos. Barcelona. 1998.

12 “Análisis del Año 2005. Política-Economía-Sociedad-Temas". Departamento de Sociología de la Universidad de Chile. Santiago de Chile. 2006. Artículo de Rodrigo Ruiz: "Disputas por la hegemonía y transformaciones culturales en el Chile actual".
} 
como difusor cultural ${ }^{13}$. La pretensión de la información veritativa y la generación de "climas de opinión sobre la realidad nacional" se imbrican en las imágenes y discursos semantizados por la televisión.

El concepto latinoamercano de nación, y sus variaciones desde el período de las sociedades desarrollistas hasta hoy, podemos rastrearlo siguiendo la reconstrucción que Cohen y Arato proponen para la sociedad civil como concepto. La sociedad civil es definible "en torno a una noción de movimientos democratizadores autolimitados que procuran extender y proteger espacios tanto para la libertad negativa como para la libertad positiva y volver a crear las formas igualitarias de solidaridad'. Estos autores introducen tres modelos de sociedad civil: liberal-funcional, estructuralista-keynesiano y "cosmopolita". Nos centraremos en los dos primeros, ya que dan cuenta de la transformación socio-cultural acaecida en Chile: cambio en el modelo de sociedad civil imperante en Chile, del estructuralista-keynesiano al liberal-funcional.

El modelo estructuralista-keynesiano, propio de las sociedades desarrollistas, asume su forma en que la sociedad civil se encuentre imbricada en relaciones administrativas, siendo las más corrientes las de sectorialización de intereses que articulan una determinada alianza sociedad-partido político.

Con la imposición del mercado como esfera de coordinación central de la vida social, lo que se produce es el triunfo hegemónico del modelo liberal-funcional. Su característica es la de comprender a la sociedad civil como espacio social autárquico y regulado por relaciones mercantiles. El estado, a diferencia de lo que sucede con el modelo estructuralista-keynesiano, pasa a asumir funciones "ambientales", y se evidencia una creciente separación entre sociedad civil y sociedad política. La consecuencia central de esta separación (el efecto hacia el cual se orienta el modelo mismo) es la progresiva tecnificación de la decisión política.

Lo principal de esta conversión refundacional es la organización de un modo de vida sistemáticamente centrado en el mercado y la represión, es decir, la desaparición de la política como ámbito de significación vital (no solo ideológicamente consciente) y como esfera de lo público en base a intereses generalizables.

La liberalización de la sociedad civil y su función reproductiva centrada en la lógica de mercado, y por consiguiente, en el consumo, tiene efectos en el flujo televisivo que se entrega, ya que otorga la pauta para que la construcción y captación de audiencias se realice de manera crecientemente generalizada en base al rating de los programas. La medición del rating opera como atractivo de la publicidad que financia los programas, y es el consumo de esos programas (ubicados segmentadamente por nichos de consumo en la "parrilla programática" de toda estación) el que impone una nueva masificación de la televisión-empresa, pues comienzan a instalarse sus productos como los de "consumo masivo", los productos de moda. Con Baudrillard, el consumo pasa de ser una función económica a ser una función cada vez más simbólica, reforzada por la capacidad de los medios para estatuir fines y legitimidades sociales ${ }^{14}$.

\footnotetext{
${ }^{13}$ CNTV, Op. Cit.

14 "La lógica de expansión del mercado comunicacional y cultural, en esta etapa del proceso modernizador ha generado, entre otros, los fenómenos de descolección y desterritorialización de la cultura, lo cual implica, por un lado, la ruptura de límites entre lo culto, lo popular y lo masivo y, por otro, que la tendencia sea a liberar a la cultura de toda fijación social, geográfica, étnica, ideológica, etc. Con ello, el menú del programa comunicacional y cultural hegemónico no sólo ofrece alternativas en términos de productos diferenciados para segmentos distintos de públicos, sino que incorpora toda la diversidad cultural susceptible de tener rendimiento económico. Naturalizados los supuestos y los fines, las exclusiones y marginaciones se fundamentan, en lo sustancial, en la lógica del beneficio y la eficacia, entendida como manifestación de productividad y rentabilidad (...) se genera así un amplio espectro de 'interactividad' y 'participación', obviamente no como una forma social activa ni espontánea, sino
} 
Entonces este público pasivo, que asiste pero no actúa en el evento escenificado, es incorporadao en el espacio de la publicidad como condición de posibilidad de los contenidos televisivos (en tanto se asuma que la propiedad de los medios debe ser privada para un mejor ajuste de éstos con su contexto social) ${ }^{15}$. Esta publicidad toma sus contornos de una cultura ad-hoc a las ideas centrales del modelo de sociedad civil liberal-funcional. En el estudio del CNTV citado, un $89 \%$ de los encuestados planteaba que el principal mal de la televisión consistía en fomentar el consumismo, especialmente en los niños (consumismo como estrategia de socialización/individualización); por lejos, el primero de los males diagnosticados. Este porcentaje aumenta el $85 \%$ con el que aparece el consumismo ante la misma pregunta en el año 2002.

\section{¿Quien se representa?}

El dispositivo mediático, tal cual ha sido problematizado en este artículo, es coherente con una sociedad que articula modos culturales de vida en función de una progresiva liberalización mercantil de los espacios de sociabilidad y asociatividad propios de la sociedad civil.

Las visiones apocalípticas acerca de estos diagnósticos (que ponen el énfasis en sus potenciales anómicos y desintegradores) no solo se encuentran generalmente ancladas en un cierto conservadurismo valórico y político de constantes referencias a un modelo de desarrollo de sociedad y de comunidad superado en el tiempo, sino que no da pie en su catastrofismo: efectivamente, la sociedad provee de nuevas formas -mínimas o no- de socialidad y de culturación: se produce, en algún momento un encuentro entre representación sobre lo social y liberalización en la experiencia.

Se puede decir que cuando un tipo de representación como el que caracterizó al Chile desarrollista, fundado en lazos orgánicos con religiones, partidos y asociaciones sociales, entra en crisis, una de las consecuencias es que progresivamente pierde fuerza la distinción de niveles de realidad entre experiencia y representación. En la profunda desconexión que se produce en el Chile dictatorial, donde se desintegran los canales que otorgaban continuidad a la experiencia subjetiva en el espacio público, una de las principales tareas de los sujetos, individuales y colectivos, consiste en encontrar formas identitarias de autoafirmación por otros medios. De este modo, tanto la represión militar como la propia resistencia popular descomponen las jerarquías asociadas a cada esfera de lo social.

Especialmente relevante resulta la minimización de la política como lugar central en la decisión de los destinos de una sociedad. Esta consecuencia de la imbricación entre represión y resistencia sobredetermina una forma de representación de la participación socio-política que se retrotrae del discurso político, y asume formas culturales fragmentarias e híbridas.

Acompañando este proceso, cada vez más los referentes identitarios hegemónicos son proporcionados por la televisión y la cultura mediática, constituyéndose éstos en nuevos espacios de continuación de las búsquedas individuales. Así, tanto a nivel de propuestas de integración social (mediatización de la

inducida y operativizada como rol al interior de un programa". Santa Cruz, Eduardo: "Estudios de Comunicaciones en América Latina y Chile: acerca de causas y azares". Cuadernos del Centro de Investigación Social. Universidad Arcis. Santiago de Chile. 1997. Negritas nuestras.

15 Eugenio Tironi fue el principal difusor de esta idea siendo el encargado de la Secretaría de Comunicaciones bajo el gobierno de Patricio Aylwin. Dirá al respecto que el verdadero pluralismo se logra con más medios privados, que expresen todo el arco ideológico, cultural y regional de Chile. En VV.AA., Ibíd. 
xenofobia, identificación cuasi-automática con los índices macroeconómicos, exaltación de la identidad nacional en torno al deporte de alto rendimiento) como de "estilos" diferenciales de vida, la propuesta de flujo estructurado de los mass media tiende a triunfar sobre las ofertas de negociación que pudieran hacer las clases populares reconvertidas en públicos mediales.

No se trata de volver a caer en lo que Martín-Barbero denominó "fascinación del poder", verdadero funcionalismo de izquierda. Pero si se toma en serio la advertencia de Thompson acerca de contextualizar las reales capacidades de articulación de los sujetos consumidores de cultura mediática, se debiera concluir que ésta es cada vez más espuria. Compartimos, en este sentido, la crítica que hace Sarlo a Martín-Barbero, acerca de su ingenua pretensión de que existen mecanismos "inherentes" de resistencia populares en lo que a dinámicas culturales se refiere; al menos, no hay antecedentes sociológicos ni antropológicos que permitan sostener dicha hipótesis.

Desde estas consideraciones podemos al menos discutir la supuesta "capacidad de negociación" que poseen las clases populares para otorgar sentidos propios en el espacio de producción de lo masivo, tesis centrales en trabajos como los de MartínBarbero y García Canclini. Esta discusión, ciertamente, tiene una relevancia mayor en función de la valoración que se le puede dar a la noción de espacio público. Con esto queremos decir que un debate más extenso sobre el espacio público no puede omitir la discusión acerca de si las modernas audiencias de públicos mantienen una esfera que asegura, de algún modo, la conformación de intereses generales. Resulta imposible hacer una recensión sobre aquello en este espacio; sólo diremos que, si se sostiene una versión crítico-reconstructiva como la propuesta por Habermas para tratar el tema, la ausencia de intereses generalizables en los modernos espacios públicos constituiría, más que opinión pública, en formación de "climas de opinión", o "esferas públicas de aparición" más que de debate argumentativo sobre fines sociales ${ }^{16}$.

Enumeraremos algunas de las consecuencias que se desprenden, a nivel de cultura política, del recorrido propuesto, con el fin de exponer, a continuación, algunas de las fisuras tentativas que se abren a una perspectiva capaz de una crítica social desde el estudio de los la comunicación mediática:

- La creciente separación entre sociedad política y sociedad civil "tecnifica" la decisión pública acerca del funcionamiento del orden social;

- El espacio público se ve obstruido en su orientación hacia el establecimiento de intereses generalizables;

- Los mass media, y en especial la televisión, pasan a ocupar la escenificación de ideas de lo social antes instaladas en las ideologías totales (religión, política, clase social) $\mathrm{y}$, por ende, constituyen referentes formales y semánticos de las nuevas construcciones identitarias;

- La misma constitución de los flujos estructurados de mensajes propuestos por los media limita crecientemente la capacidad de articulación de los sujetos populares masificados, y por ende, van mutando progresivamente sus propias identidades culturales;

- La legitimidad del orden público pasa, crecientemente, por el asegurar una escenificación verosímil, creíble y normativamente compartida sobre "la realidad".

No obstante, las condiciones de la cultura política actual no son, en modo alguno, monolíticas y perennes. Se pueden enunciar, a modo de hipótesis, algunas

\footnotetext{
${ }^{16}$ Ver HABERMA, Jürgen: "Historia y Crítica de la Opinión Pública”. Editorial Gustavo Gili. México. 1994; Thompson, Op. Cit. Por otro lado, sólo un debate absolutamente informado por un postmodernismo funcionalista al estilo del asumido por Lyotard o por la figura del ironista en Rorty podría prescindir de este tópico.
} 
condiciones críticas que el orden de dominación puede presentar, sin pretender establecer tendencias de ruptura ni otro tipo de ejercicio analítico-profético:

- En primer lugar la creciente tecnificación de la decisión política, sumada a una fuerte tendencia hacia el privatismo civil, puede conducir a déficits de legitimación de la administración política. Algo de eso vivimos en Chile hoy: creciente apatía por una forma específica de ejercer las funciones políticas. Esta apatía concreta (para distinguirla de cualquier tipo de apatía por la política per se) se corresponde con lo que Habermas denomina crisis de legitimación latente.

- Segundo, la dinámica de apertura e incorporación cultural de estándares transnacionalizados, formatos probados y valores radicados en el respeto de las diferencias y las opciones particulares, al parecer va cerrando su ciclo en tanto "alcanzamos" un estatus mínimo de país culturalmente "en sintonía" con las tendencias globales (pero muy occidentales). En este marco, queda mucho aún por cristalizar de esas tendencias culturales y normativas que han ingresado, no obstante, para quedarse, al menos en el mediano plazo. El proceso de sedimentación cultural instalado abre el problema de cuál será el tipo específico de decodificación y representación que hagan los diversos actores socio-políticos y culturales, y cómo logran encauzar dichas representaciones en espacios públicos o escénicos. Todo lo cual, evidentemente, alterará las percepciones hegemónicas y abrirá nuevas contradicciones. Que ellas se expresen o no como conflictos políticos, o condicionen modificaciones a la cultura política, resulta hoy impredecible.

- Aún la reapertura de un espacio público temático más que escénico constituirá, sin duda, un foco de conflicto. La reinvención de los contenidos que luchan por llenar los significantes políticos pareciera ser, hoy, una disputa abierta a nivel planetario. En este marco, ha venido cobrando fuerza la demanda ciertamente propia de la sociedad civil por sistemas más solidarios y auténticamente humanos, sea lo que sea que signifique esto para cada actor o sector.

- Podemos mostrar una forma que ha sido efectiva en la resistencia a la hegemonía cultural del mercado: ciertos grupos que se guían por un discurso indiscutiblemente conservador en el plano valórico. Aun en la proclamación de su derrota en tanto garantes de valores tradicionales y orgánicos, su articulación discursiva con otros tipos de discursos "sociales" -y aquí sólo alcanzo a hacer referencia a la "preocupación social" en sentido lato- puede abrir flancos de resignificaciones, toda vez que es previsible que las instituciones que soportan este conservadurismo valórico (en especial la Iglesia Católica y sus instituciones asociadas) no dejarán de ser actores relevantes en el corto plazo.

- Por último, no se puede desechar la posibilidad de que la continuación de los mecanismos culturalmente autoritarios por medios no autoritarios (base técnica de la actual pasividad individual) sea cuestionada desde configuraciones identitarias subalternas: mujeres, etnias, jóvenes (las recientes movilizaciones secundarias algo dicen sobre esto) u otro tipo de márgenes culturales pueden alcanzar la potencia de interpelar públicamente, desde la particularidad que los constituye, un descentramiento de la mirada y de la experiencia sobre lo social, de consecuencias también difíciles de prever. 